\title{
Dialogic vs. Formalist Teaching in Developing Argumentative Writing Discourse and Reducing Speaking Apprehension among EFL Majors
}

\author{
Hany Ibrahim Musa \\ College of Education, Al-Azhar University, Egypt
}

\begin{abstract}
The current study, sought to investigate the influence of both formalist and dialogic teaching on EFL majors' argumentative writing and speaking apprehension. By using a positivistic experiment research design, and on analysing students' argumentative writing essays, it has been proved that both teaching approaches developed students' argumentative writing. However, statistical analysis showed that the dialogic teaching group students surpassed those of the formalist teaching. In addition, results revealed that speaking apprehension levels of the dialogic teaching students have significantly been reduced rather than those of the formalist teaching. The study ended with some conclusion and recommendations for further research.
\end{abstract}

Index Terms — dialogic teaching, argumentative writing, speaking apprehension, EFL students

\section{INTRODUCTION}

This study was derived by a basic ontological belief that language has an intersubjective nature as a social system through which we organise and produce social reality (language products) via speaking and writing. It is a process of dialogism which conceptualises knowledge as a multivoiced conversational turn in which people produce it together rather than an individual possession or monologism. The presenter of such knowledge responds to previous utterances and presents future ones. This ontological assumption corresponds with a constructivist epistemological view about learning that people learn by using what they know to construct new understandings and that teachers can apply and enhance such constructive beliefs by offering "instructional designs and practices that provide students with frequent and sustained opportunities to engage in dialogic learning" (Juzwik, Borsheim-Black, Caughlan, \& Heintz, 2013, p. 5). With this in mind and drawing on other prior research, the aim of the study has been to see how the concept of dialogic teaching, comparing the formalist conventional teaching, relates to the actual interaction of students in the argumentative writing classroom.

Dialogic teaching: A theoretical basis

The concept of dialogic enquiry and teaching owes much to the work of Vygotsky, and Bruner (DATE) whose work and ideas have stimulated a research paradigm that highlights the social construction of the individual and his interaction with others as a key issue for learning. Their work was revisited in the 1970s and 1980s, by Bakhtin who conceptualised the idea of dialogic pedagogy. His constructs such as 'dialogicality', 'social language', 'speech genre' and dialogic meaning-making provide concrete mechanisms for extending Vygotsky's claims about the social origins and social nature of human mental functioning. This was a new era which suggested the learner to "play an active role in developing a personally constructed understanding of the curriculum through a process of dialogic interchange" (Lyle, 2008, pp.224-225).

Bakhtin made a distinction between dialogic and monologic discourse. Monologic discourse is an instrumental approach to communication geared towards achieving the teacher's goals and remains firmly in control of the goals of talk. Controversially, dialogic talk is concerned about encouraging communication through authentic exchanges where there is genuine concern for the views of the talk partners and effort is made to help participants share and build meaning collaboratively. Baktinian concepts of dialogic meaning encompass the view that dialogue is not simply between people but between the frames people use to categorise experiences (Gurevitch, 2000; Skidmore, 2006).

Dialogic teaching, then, is a general pedagogical approach that capitalizes on the power of talk to promote students' thinking, learning, and problem solving (Alexander, 2006). The growing body of literature on dialogic teaching (Alexander 2006) ascribes varied labels: dialogic instruction (Nystrand et al. 1997), dialogic learning (Hawkins, 2004), dialogic pedagogy (Skidmore 2006) and dialogic inquiry (Watkins, 2005), but the steady message is for supportive and substantive opportunities for involved talk with content - to explore, challenge, reconsider, and extend ideas in ways that enhance student learning. It needs learners to extend the world of the text through inferring the possibilities and arguing for more aspects and solutions. Dialogic teaching allows for a dialogic space between the reader and the text through synthesizing stories outside the text (Wikinson, et al, 2017). It requires teachers to allow for a broad repertoire of discourse practices and to be able to professionally use different types of discourse to address the specified instructional goals assigned for students. Although these discourse practices include traditional kinds of talk, such as 
recitation and exposition, dialogic teaching privileges discussion and dialogue because they have the greatest cognitive potential and are 'the forms of talk which are most in line with prevailing thinking on children's learning' (Alexander, 2006, p.103).

In addition to the strategic use of talk, Alexander identified five principles of dialogic teaching in the classroom:

- Collective: teachers and students address learning tasks together, whether as a group or a class, rather than in isolation;

- Reciprocal: teachers and students listen to each other, share ideas and consider alternative viewpoints;

- Supportive: students articulate their ideas freely, without fear of embarrassment over 'wrong' answers, and they help each other to reach common understandings;

- Cumulative: teachers and students build on their own and each other's' ideas and chain them into coherent lines of thinking and enquiry;

- Purposeful: teachers plan and facilitate dialogic teaching with particular educational goals in view. (Alexander, 2006)

Higham, Brindley and Van de Pol (2014) added two other propositions that are at the heart of dialogic education. The first is that dialogue is pivotal to student learning and understanding across all stages and courses because it underpins the process of learning to think. This is truly aligned with Vygotsky who argued that the true direction of thinking is not from the individual to the group, but from the social to the individual. The second proposition is that meanings and understandings are co-constructed within dialogue rather than transmitted from one person to another (Wegerif 2011). As a result of participants in dialogue attempting to fill in the gap between divergence and convergence in talk when two or more differing perspectives come into contact, new meanings emerge, and participants, then, realise the value of understanding these ideas and appropriating them as part of their world views.

Dialogic teaching then, is not just using language to exchange ideas in an educational context. "When students are working collaboratively in groups, they co-construct meaning over successive utterances in order to get things done together" (Haneda \& Wells, 2008, 117). The expectation of reciprocity between students and teachers as listeners and speakers are true but teachers typically make both the first and the last move in a triadic dialogue form of exchange; teacher initiates; student responds and then teacher follows up.

\section{Dialogic teaching and EFL students}

Participating in in the range of discourse genres across the curriculum necessitates the use of dialogue to develop students' discursive competences. Such participation in dialogic interaction in the classroom is particularly beneficial for a number of reasons. First, dialogic interaction provides not only 'comprehensible input of Krashen, but also opportunities to learn how to engage in the genres of the different academic disciplines, for example literature or issues of interest, so that they may become academically competent participants. When they are called on to play a role in the co-construction of curriculum knowledge, they are likely to have opportunities to produce longer and complex contribution as they assume the role of active participants in discussions, leading to the production of comprehensible output.

Second, while students are using their language resources to contribute to the ongoing classroom talk, they simultaneously learn the social and communicative strategies needed to access the academic content (e.g. when to contribute, how to express their ideas clearly using appropriate discourse strategies, etc.). Curriculum has a tripartite nature which poses academic, social and communicative demands, and thus, students need to learn how to communicate with others in an interpersonally appropriate manner in a particular situation and how to express social relationships, while at the same time learning the academic content.

Third, as students contribute to the ongoing construction of knowledge, they are likely to encounter alternative perspectives on the topic under discussion, expressed by students as well as the teacher, like those in argumentative discourse. Such opportunities to listen to and express differing perspectives expose them to diverse language models and henceforth developing their language competences (e.g. different ways of expressing ideas and the language of negotiation, such as agreeing/disagreeing with someone). (Echevarria \& Powers, 2006 ; Haneda \& Wells, 2008).

\section{Dialogic teaching and argumentative writing}

Argumentation in general has been theorised as "dialogic" or "conversational entry" (Juzwik, Borsheim-Black, Caughlan, \& Heintz, 2013, p. 34) and as a "social practice" (Newell et al., 2014, p. 112). It is a form of participating in dialogue in the world in which someone takes a stance within an ongoing conversation and defending and supporting its logics. The ability to build arguments is a crucial lifelong skill for all individuals and a central educational goal in all school subjects. This empowers students to formulate reasoned opinions and thus to cope with the increasing complexity of knowledge. Accordingly, it can be considered as a challenging topic for EFL majors due to the different and difficult aspects embedded within.

Despite this complexity in nature, the formalist approach is the one dominating in most writing argumentation classrooms. In this approach, teachers emphasise form over content by asking students to fit content to the traditional five paragraph theme, often identified as thesis, claims, evidence, counter-argument and conclusion (VanDerHeide, Juzwik and Dunn, 2016)). While this type of writing does not typically require students to consider nuanced arguments or to think about how form might influence the articulation of an argument, it is not applied this way in the EFL classroom in the college. It is taught as a genre of writing with little emphasis on form rather than on meaning. The 
efficacy of such approach is supported by some intervention studies (e.g., Nussbaum \& Schraw, 2007; Yeh, 1998) that have shown that with more instruction in form, such as structure-specific graphic organizers, students' argument writing does improve, as measured by holistic or analytic measures similar to those used in standardized testing environments.

\section{Dialogic teaching and speaking}

Students learning English as a foreign language have difficulty expressing their opinions orally. As such, avoiding to express opinions in an argumentative discourse context which depends mainly on ongoing argumentation and negotiation is problematic. Following Alexander, dialogic teaching addresses this problem. It is a general pedagogical approach that capitalises on the power of talk to foster students' thinking, learning, and problem solving; features that argumentative writing is mainly based on. Consequently, it requires teachers to have a broad repertoire of discourse practices and to be able to strategically use different types of discourse to address specific instructional goals for their students. Such discourse practices might include traditional kinds of talk, such as recitation and exposition, however, dialogic teaching privileges discussion and dialogue and hence reduces speaking apprehension that most EFL students face (Haneda \& Wells, 2008). As such, discussion and dialogue, then, have the greatest cognitive potential and are 'the forms of talk which are most in line with prevailing thinking on students' learning' Alexander $(2006,103)$.

\section{The purpose of the study}

Despite different strategies to promote more interactive approaches to teaching and learning, traditional monologic teacher-centered practices predominate in teaching argumentative writing. Such formal lecture model of instruction fails to acknowledge the socially constructed nature of writing. This research study attempted to contribute to the line of research concerning with dialogic education by investigating the process of applying the two teaching models; dialogic vs formalist, in an EFL educational environment in enhancing the learners' argumentative writing and reducing their level of speaking apprehension. It tried to have an answer to the following main question:

What is the effect of dialogic vs. formalist teaching in developing argumentative writing discourse among the $3^{\text {rd }}$ year EFL majors and reducing their level of speaking apprehension?

\section{Research Questions}

The above main research question can be sub-divided into the following ones:

1. What is the effect of the formalist teaching on enhancing the argumentative discourse of $3^{\text {rd }}$ year EFL students?

2. What are the influences of the formalist teaching on reducing the level of speaking apprehension of $3^{\text {rd }}$ year EFL students?

3. What is the impact of the dialogic teaching approach on enhancing the argumentative discourse of $3^{\text {rd }}$ year EFL students?

4. What is the effect of the dialogic teaching on reducing the level of speaking apprehension of $3^{\text {rd }}$ year EFL students?

5. Is there a difference between formalist teaching and dialogic teaching in developing the argumentative discourse of $3^{\text {rd }}$ year EFL students?

6. Is there a difference between formalist teaching and dialogic teaching in reducing the level of apprehension of $3^{\text {rd }}$ year EFL students?

\section{METHODOLOGY}

\section{Design and procedures}

A positivistic experimental research design was selected to examine the effects of dialogic vs formalist approach on developing $3^{\text {rd }}$ year EFL students argumentative writing skills and reducing their level of speaking apprehension. For this purpose, the present study included two groups; One is experimental group in which the dialogic teaching (DT) was implemented and second is the control group in whish formalist teaching (FT) was administered. All students in the two groups were gathered together in three collective sessions to be admitted to the programme and the distribution on the two groups. They decided about the topics to be covered during the whole programme and the final decision was to be trained on the following ideas:

1. Internet is a mixed blessing

2. Social network media is a waste of time

3. Co-education: what is for and what is against?

4. Genetically modified food

5. Private and state university education

6. International and national education

The programme lasted for 11 weeks and the pre-administration of the instruments were administered before implementing DT and FT activities in the lecture room. The post-tests were administered at the end of the $11^{\text {th }}$ week.

Either adopting a formalist or dialogic approach in enhancing argumentative discourse among students, the following procedures, taken from Ferretti et al. (2009), were used to graphically represent the structure of the arguments presented in the writing samples: 1) the student offered one standpoint on social networks, 2) students provide four reasons for this standpoint; these reasons are presented as two multiple arguments with two supporting details, 3) the reasons are directly supported by subordinating reasons, 4) students provide a counterargument for the reasons, as well as a rebuttal (a statement that refutes or undermines an alternative standpoint) for the counterargument in order to strengthen the 
writer's stance, 5) and lastly, they include one rhetorically functional repetition in the essay; a statement that restates previously expressed reasons, arguments, or standpoints.. The essay, then, contains 14 elements: one standpoint, four reasons, six subordinating reasons, one counterargument, one rebuttal, and one rhetorically functional repetition. Finally, cohesive and coherent feature of writings were also highlighted and analysed to measure the extent the elements of argumentative discourse are presented logically by the writer and contribute in support of the writer's premise; and the extent the writer either over-or under-used cohesive markers to signal relationships between parts of his or her text.

\section{Participants}

The participants of the study were 74 students enrolled randomly in the two groups where the DT group had 38 and FT group had 36 ones. Attempts were made to ensure homogeneity among the participants. Specifically, the variables that might influence the results, such as age, educational background, socio-economic demography and their aim to attend an EFL program were tightly controlled before the research.

On the other hand, the study has various limitations. The sample of 74 students may not represent the whole population. The number of participants was limited due to the nature of the study in the College of Education of AlAzhar University. Also possible idiosyncratic differences among participants cannot be controlled in any way. Taking these limitations into account, the results should be interpreted with caution.

\section{Instruments}

To collect the data concerning students' writing, an Argumentative Writing Test (AWT) and a scoring rubric were developed by the researcher. In the writing test, students were asked to write an argumentative writing about "private and state university education". The essays were analysed and scored for elements of the argumentative writing discourse explained earlier using the scoring rubric. To reach the score, the contents of each essay were graphed in a diagram. This process is referred to as "graphing" (Ferretti et al., 2009). The purpose of this graphing was to: (a) identify the student's standpoint(s), and to (b) recognize the student's reasons to support for the standpoint. Furthermore, it was important to (c) identify alternative standpoint(s), which are standpoints of other people that the student disagrees with, (d) identify reasons for the alternative standpoint, (e) identify counterarguments that could be used to object to or undermine the student's standpoint, which are potential criticisms of either the student's standpoint or reasons for the student's standpoint that could be used to enhance the alternative standpoint, (f) identify rebuttals of the alternative standpoint, which are propositions that either attack an alternative standpoint or undermine counterarguments and thereby strengthen the student's standpoint, (g) identify an introduction that foreshadows what is to follow in the student's presentation of the argument, (h) identify a conclusion that brings together what the student has written, (i) identify functional and nonfunctional statements that include information that is irrelevant to the topic.

After each element was graphed, the elements were tallied by counting the number of elements present in the graphing structure for each element of argumentative discourse. Then a s score for coherence and cohesion was also added to the other ones to give a total score for each paper.

As noted, the researcher scored all the 74 essays written by students using the holistic measures previously described. In order to determine inter-rater reliability a second rater, who was unfamiliar with the design and purpose of the study analysed and scored 16 essays independently (approximately 40\%). The analysis of Cohen's Kappa for the quality, coherence, and cohesion measure revealed that inter-rater reliability for these scales all fell within the "very good" range: the kappa value was 0.86 . An indicator that the holistic scoring of the test is reliable.

In addition, A five-point Likert speaking apprehension inventory (SAI) consisted of 10 items, was developed and utlilised by the researcher to gauge students' level of apprehension when asked to communicate in class either with the teacher or with their peers. The inventory was conducted twice at the beginning of the 3rd week after two weeks of teaching and at the end of the 11th week.

To ensure the validity of the scale content, a standard criterion for the development of valid and reliable questionnaires followed by Brown (2001) and Dornyei (2003), was selected by reviewing the relevant literature. Moreover, in order to keep respondents' attention and check their truthfulness in answering the statements, the items were randomly mixed with others to avoid a fixed pattern of marking the rating scale. Finally, these items were submitted to four experienced experts for more scrutiny, and based on their suggestions, the final version was prepared for administration on the participants of the study. For reliability, the overall Cronbach's alpha was calculated and the result was .83 which shows that this scale was reliable.

\section{RESUltS AND ANALYSIS}

As mentioned earlier, two instruments were used for data collection to accomplish the purpose of the study. The data obtained was analysed in accordance with the study questions that can be grouped under five major themes, namely: 1) Formalist teaching and argumentative writing; 2) Formalist teaching and speaking apprehension level; 3) Dialogic teaching and argumentative writing; 4) Dialogic teaching and speaking apprehension level; 5) Formalist vs Dialogic in both argumentative writing and speaking apprehension. Findings will be presented based on these themes.

\section{A. Formalist Teaching and Argumentative Writing}

Table (1) displays the results of the descriptive and the inferential statistical analyses between formalist teaching students' scores on the pre-posttest : 
TABLE I

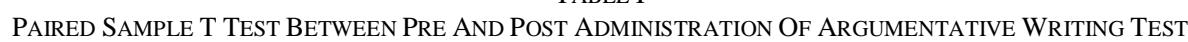

\begin{tabular}{|c|c|c|c|c|c|c|}
\hline Group & Treatment & No. & Mean & Std. Deviation & T-Value & Sig. (2tailed) \\
\hline \multirow{2}{*}{ FTG } & Pre & 36 & 8.66 & 3.38 & \multirow{2}{*}{8.62} & \multirow{2}{*}{0.00} \\
\hline & Post & 36 & 14.75 & 4.27 & & \\
\hline
\end{tabular}

The above results specified that there was a statistically significant difference between the mean scores attained by the FTG learners (pre and post-test) in the argumentative writing. Results of the $t$-test yielded 8.26 which is significant (sig. $=0.002$ tailed $=\mathrm{P}<0.05$ ). Over and above, the figure (1) below delineates the difference in the argumentative writing formalist group before and after the treatment showing that there was an obvious difference between the mean scores of the FTG learners in the pre and post argumentative writing test.

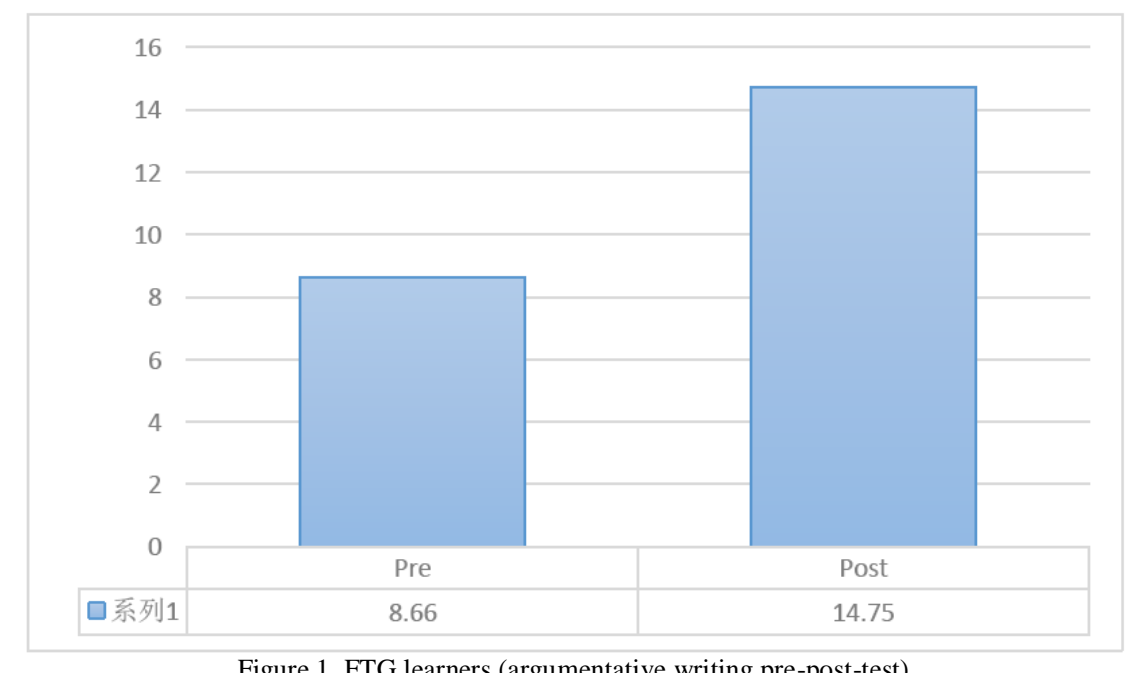

Figure 1. FTG learners (argumentative writing pre-post-test).

Additionally, to validate the results obtained, the effect size (how much variance in argumentative writing was a result of the formalist teaching) was computed using the Cohen's $d$ formula, which yielded $(d=2.91)$ identifying that more $97.7 \%$ of the improvement in the argumentative writing may be attributed to the formal teaching applied. Hence, in the light of the results drawn above, the formalist teaching has a considerable effectiveness in developing the argumentative writing among the study participants.

\section{B. Formalist Teaching and Speaking Apprehension}

Table (2) displays the results of the descriptive and the inferential statistical analyses between formalist teaching students' scores on the pre and post administration of the speaking apprehension inventory:

TABLE II

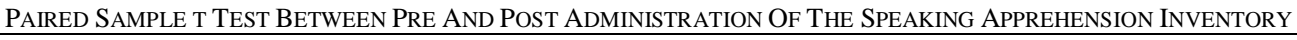

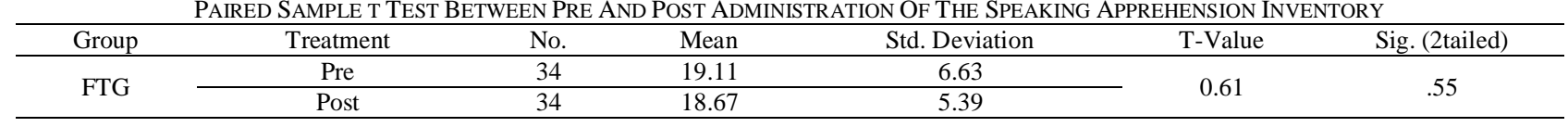

The results exposed above pinpointed that there was no statistically significant difference between the mean scores attained by FTG learners in relation to their responses to the speaking apprehension inventory before and after the treatment. Results of the $t$-test yielded $(0.61)$ which was not significant (sig. $=0.552$ tailed $=\mathrm{P}>0.05$ ). Among other things, the figure (2) below delineates the difference in the level of speaking apprehension before and after the treatment. 


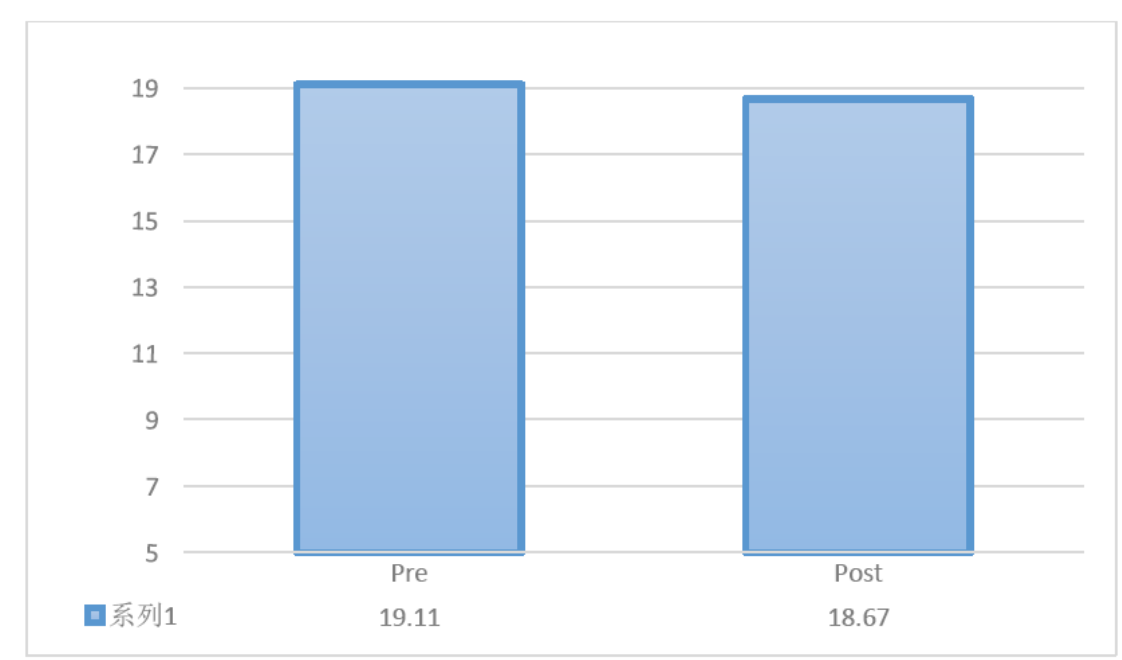

Figure 2. FTG learners (speaking apprehension before and after treatment).

Figure (2) above shows that there was no noticeable difference between the mean scores of the FTG learners in relation to the speaking apprehension inventory before and after the treatment. Consequently, formalist teaching was not effective in reducing the level of speaking apprehension among the study participants.

\section{Dialogic Teaching and Argumentative Writing}

Table (3) discloses the results of the descriptive and the inferential statistical analyses between dialogic teaching group learners' scores on the pre-posttest:

TABLE III:

Paired SAmple t Test Between PRe AND Post Administration Of ARgumentative Writing Test

\begin{tabular}{ccccccc}
\hline Group & Treatment & No. & Mean & Std. Deviation & T-Value & Sig. (2tailed) \\
\cline { 2 - 6 } DTG & Pre & 34 & 8.76 & 2.91 & \multirow{2}{*}{13.17} & 0.00 \\
& Post & 34 & 18.97 & 5.27 & \\
\hline
\end{tabular}

The results shown above quantified that there was a statistically significant difference between the mean scores attained by the DTG learners (pre and post-test) in the argumentative writing. Results of the $t$-test yielded (13.7) which is significant (sig. $=0.00$ 2tailed $=\mathrm{P}<0.05$ ). Above and beyond, the figure (3) below outlines the difference in the argumentative writing showing that there were obvious differences between the pre-test and the post-test.

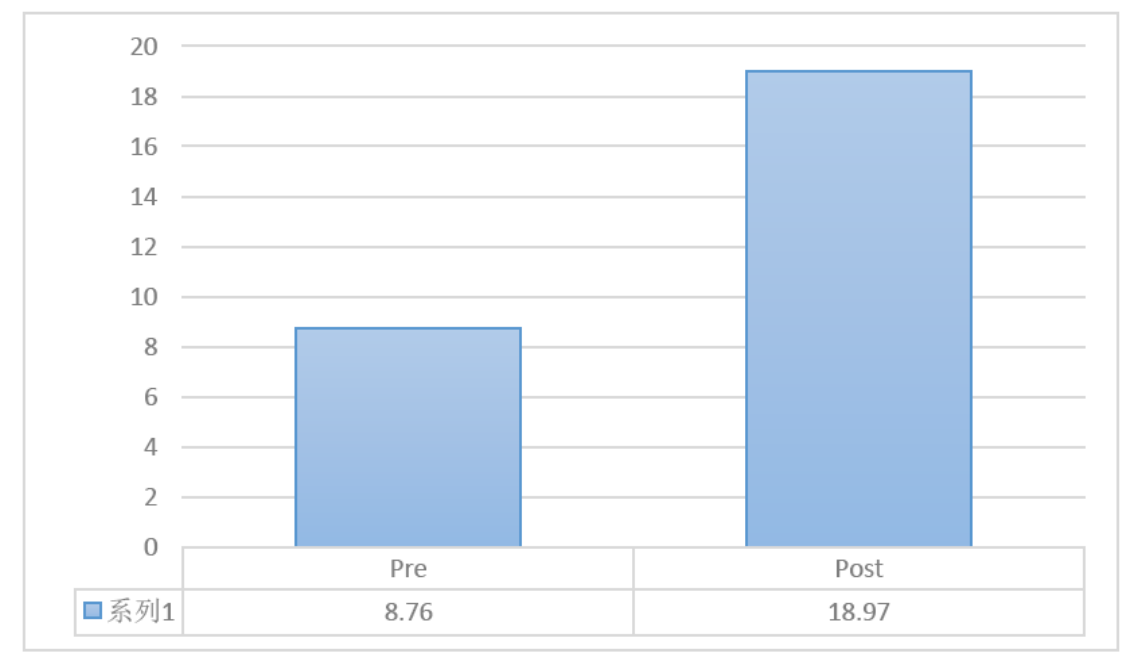

Figure 3. DTG learners (argumentative writing pre-post-test).

Furthermore, to authenticate the results of the statistical analysis, the effect size was computed using the Cohen's $d$ formula, which yielded $(d=4.58)$ determining that more than $97.7 \%$ of the improvement in the argumentative writing of the DTG learners may be attributed to the dialogic teaching applied. Accordingly, the results drawn above manifested the effectiveness of the dialogic teaching in developing the argumentative writing among the study participants.

\section{Dialogic Teaching and Speaking Apprehension}

Table (4) exhibits the results of the descriptive and the inferential statistical analyses between dialogic teaching group students' scores on the speaking apprehension: 
TABLE IV

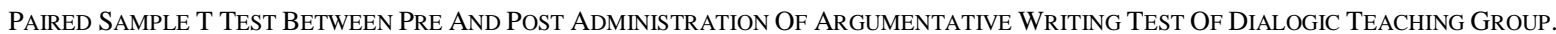

\begin{tabular}{ccccccc}
\hline Group & Treatment & No. & Mean & Std. Deviation & T-Value & Sig. (2tailed) \\
\hline \multirow{2}{*}{ DTG } & Pre & 36 & 26.41 & 8.28 & \multirow{2}{*}{6.58} & 0.00 \\
\cline { 2 - 6 } & Post & 36 & 18.86 & 4.40 & & \\
\hline
\end{tabular}

The results shown above uncovered that there was a statistically significant difference between the mean scores attained by the DTG learners in relation to their responses to the speaking apprehension inventory before and after the treatment. Results of the $t$-test yield (6.58) which was significant ( $\mathrm{sig} .=0.002$ tailed $=\mathrm{P}<0.05$ ). Concurrently, the figure (4) below delineated the difference in the speaking apprehension level before and after the treatment.

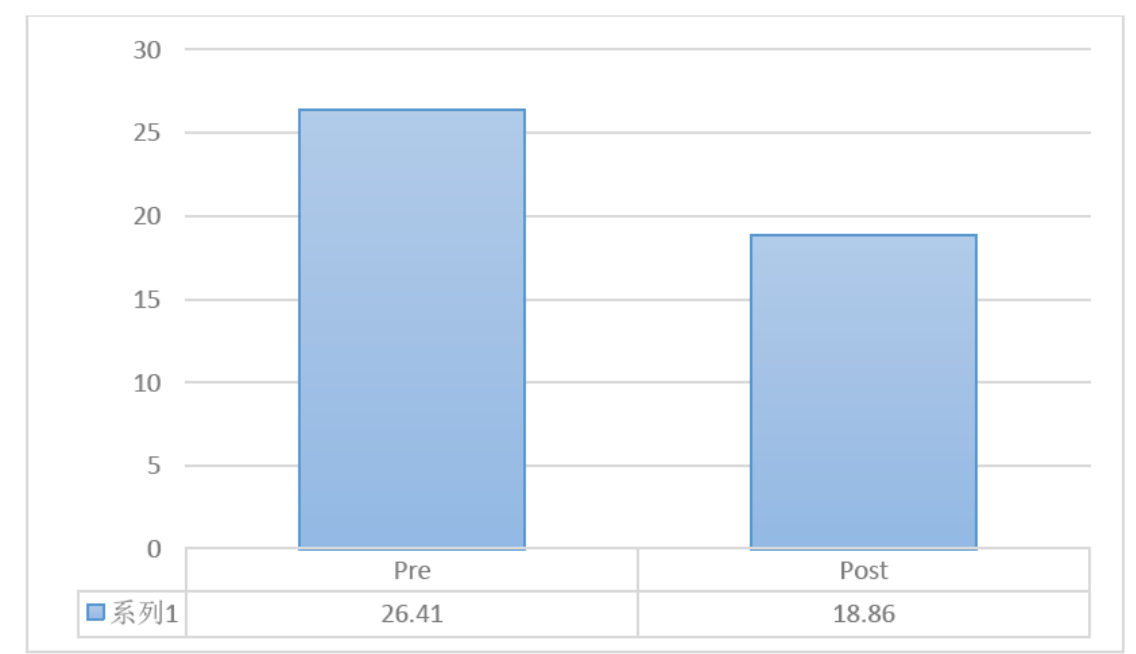

Figure 4. DTG learners (speaking apprehension before and after treatment).

To verify the above results, the effect size (how much variance in speaking apprehension was a result of the DTG) was computed using the Cohen's $d$ formula, which yielded $(d=2.22)$ disclosing that more than $97.7 \%$ of the reduction in the speaking apprehension of the target group was attributed to the DT. Accordingly, the results drawn above indicated the effectiveness of the DT in reducing the level of speaking apprehension among the study participants.

\section{E. Formalist versus Dialogic Teaching on Argumentative Writing}

Table (5) below, compares the posttest scores of both the FTG and DTG groups. The purpose is to mean scores to reveal the difference in the argumentative writing before and after the treatment:

TABLE V

INDEPENDENT SAMPLE T TEST BETWEEN POST ADMINISTRATION OF ARGUMENTATIVE WRITING TEST OF THE DTG VERSUS FTG.

\begin{tabular}{llllll}
\multicolumn{5}{c}{ INDEPENDENT SAMPLE T TEST BETWEEN POST ADMINISTRATION OF ARGUMENTATIVE WRITING TEST OF THE DTG VERSUS FTG. } \\
\hline Group & No. & Mean & Std. Deviation & T-Value & Sig. (2tailed) \\
\hline FTG & 36 & 14.75 & 4.27 & 3.69 & 0.000 \\
\hline DTG & 34 & 18.97 & 5.27 & 3 \\
\hline
\end{tabular}

The results publicized above displays that there was a statistically slight difference between the mean scores attained by the FTG and DTG groups on the post-administration of the argumentative writing test in favour of the DTG. Results of the $t$-test yielded (3.69), which was significant (sig. $=0.00$ 2tailed $=\mathrm{P}<0.05$ ). Figure (8) below delineates this difference. 


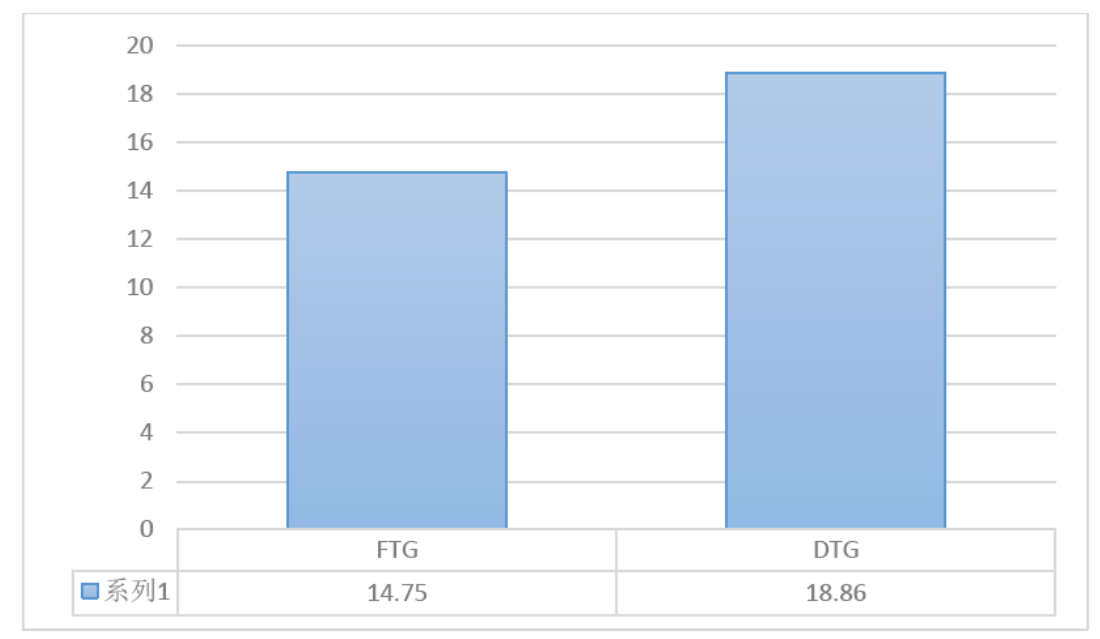

Figure 5. FTG and DTG (argumentative writing).

Substantiating the results of the statistical analysis entails computing the effect size (how much variance between the two groups in the argumentative writing level as a result of the treatment). Cohen's $d$ formula yielded $(d=0.89)$ meaning that $96.4 \%$ of the improvement in the argumentative writing of the DTG may be attributed to the treatment.

\section{F. Formalist versus Dialogic Teaching (Speaking Apprehension)}

Table (6) demonstrated the results of the statistical analysis as a comparison was held between the posttests of the FTG and DTG groups mean scores to reveal the difference in the speaking apprehension before and after the treatment:

TABLE VI

INDEPENDENT SAMPLE T TEST BETwEEn POST AdMINISTRATION OF SPEAKING APPREHENSION INVENTORY OF THE DTG VERSUS FTG.

\begin{tabular}{llllll}
\hline Group & No. & Mean & Std. Deviation & T-Value & Sig. (2tailed) \\
\hline FTG & 34 & 26.14 & 8.44 & 3.67 & 0.00 \\
\hline DTG & 34 & 19.58 & 6.07 & 3 & \\
\hline
\end{tabular}

The results publicized above displays that there was a statistically significant difference at 0.5 level between the mean scores attained by the FTG and DTG groups (post administration) in the speaking apprehension inventory in favour of the FTG. Results of the $t$-test yielded (3.76), which was significant (sig. $=0.002$ tailed $=\mathrm{P}<0.05$ ). In this context, the figure (6) below delineates this difference.

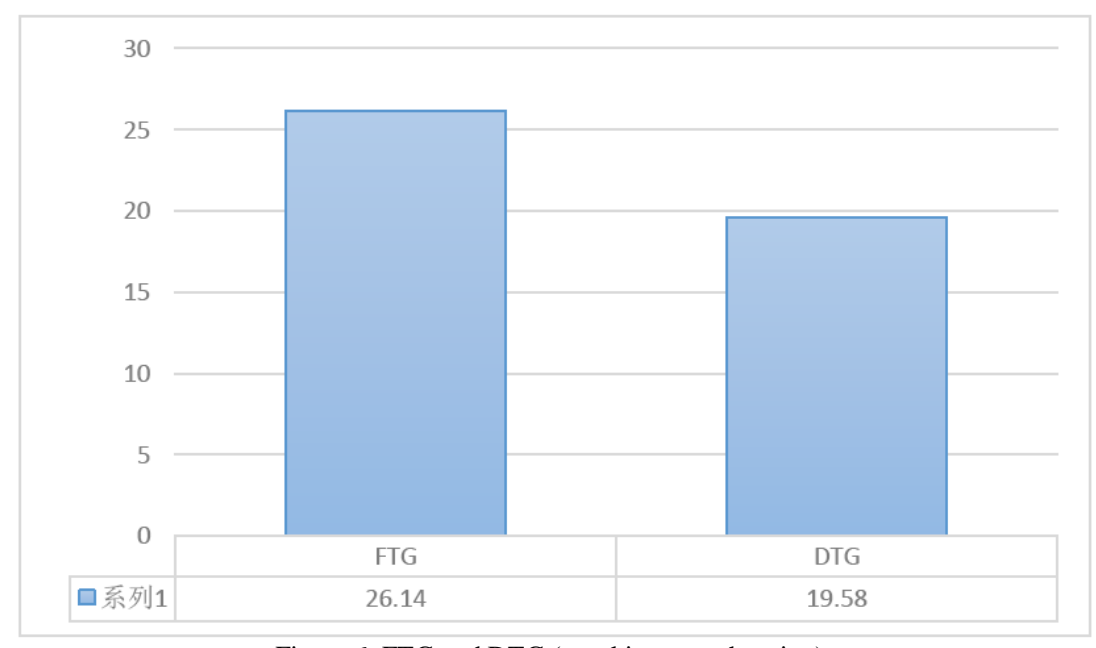

Figure 6. FTG and DTG (speaking apprehension).

Substantiating the results of the statistical analysis entails computing the effect size (how much variance between the two groups in the speaking apprehension level as a result of the treatment). Cohen's $d$ formula yielded $(d=0.90)$ meaning that $82 \%$ of the improvement in the speaking apprehension of the DTG may be attributed to the treatment.

\section{DISCUSSION}


This study has reported the results of an 11 weeks intervention utilising both dialogic and formalist teaching on students' argumentative writing skills and speaking apprehension. The quantitative analyses indicated that although participation in both groups had significantly changed their argumentative, the mean scores of the dialogic education students were higher. In addition, the dialogic education group outperformed those of the formalist teaching in reducing the level of speaking apprehension.

\section{Formalist and dialogic education in the argumentative writing classroom}

Teaching either in the formalist or in the dialogic group has significantly and positively changed students' argumentative writing skills. One reason for such developments in both groups is the time factor. Teachers of writing, in the EFL classes in the college, do not allocate specific time for teaching students argumentative writing discourse. They teach them the different genres of writing in general, one of them is argumentative, and then ask them to write an essay about one of these types. When students were given the time and the chance to know and read about argumentative writing construction, and practice such knowledge, their argumentative skills were developed to such a significant way. Peregoy \& Boyle (2007) assured this idea confirming that providing EL learners with sufficient time and extensive opportunities to write not only improves their writing skills, but fosters language acquisition in general.

Another reason for interpreting such result is that students in both groups have received training on the different constituents of an argumentative essay in a form of graphing which is used later for assessing their writings. This helped them recongise the different ways of building such sentences and how to place them in the right position in the essay which linked both instruction and assessment process. (Leer \& Runck, (2016) supported this idea. They confirmed that students need "more guidance, structure, and explicit instruction" than is traditionally expected in a workshop context". Hosp (2010, p. 3) also said:

"When teachers use assessment data to make their instructional decisions, student performance increases...training preservice and inservice teachers to more effectively and efficiently collect and use assessment data to make instructional decisions for their students and classes should be a core component of any professional development".

The nature of the topics students chose to write about is another reason for students' argumentative writing skills development. Topics such as co-education, internet or private and state university education, which they chose themselves to write about, are such hot topics that everybody in the Egyptian society is talking about nowadays. Despite the expensive cost of private education, most middle and high class Egyptians are enrolling their students in private education. This permeates for better education and hence better jobs. Students were very enthusiastic while either talking about and then write or go direct to write about the different opinions.

\section{Dialogic teaching and argumentative writing}

In addition to the aforementioned justifications to the positive scores students obtained, statistics have revealed that dialogic teaching students' scores on the argumentative writing test outperformed those of the formalist teaching. The dialogic teaching class was characterised by providing students with the opportunities for dialogue and discussion. When teachers include students' voice and language into the classroom discourse, this helps them to think more deeply about focal topics (Winn \& Johnson, 2011). In particular, in our context of argumentative writing, discussions become an invaluable element of instruction as they encourage reflection and evaluation of multiple perspectives presented in the discussion (McCann, 2010). Additionally, inviting students to participate in the discussion of important issues validates their ideas and experiences and helps them to realize how such experiences can be transferred into writing (Winn \& Johnson, 2011).

Another reason for the outperformance of the dialogic teaching group is that the class was characterised by collaboration and inquiry activities. This helped lessening the cognitive demands of the writing tasks on students and enhancing personal relationships. when Students were engaged in dialogue, they effortlessly produce the very elements of elaborated argument that often seem to be missing from their written essays, such as acknowledging and dealing with alternative perspectives on the issue. They also shared their writings with their peers and benefited from additional assistance provided to them.

\section{Discourse patterns}

Results obtained revealed reduction in the level of speaking apprehension among the dialogic teaching group. This is quite normal since both dialogic education and argumentation operate through negotiating ideas. On aalysing the students' talk, three discourse patterns emerged; generalisations; communicative dispute; and co-construction of ideas. During talk, students are encouraged to bring with them notes about the topics discussed to prepare their ideas and support them. However, most of the ideas presented were exploratory, informal and general in nature. For instance, when asked about social media or genetically modified food, they did not have scientific or official documents to support their ideas and most of the supporting details were unofficial.

Most of the discourse emerged was similar to a communicative dispute among them. This dispute emerged when one of the students asked a question to explain the idea discussed. such struggle consisted of the majority of turns in discussion and typically occurred as a result of the generalisation in the dialogue. Finally, generalisation and communicative dispute or struggle allowed the students to co-construct their knowledge. During session, when they made sense of information, they try to co-construct the meaning to determine what can or can not be done. These discourse patterns written down on the notes provided, were very helpful in organaising the ideas while writing to 
determine the argument and counter argument of the topic discussed. Teachers utilised this dialogue not to control learned knowledge but to let students acquire new understanding; this scaffolding dialogue used structured questions which built on each other in order to solve a problem that is too difficult for students (Alexander, 2006).

\section{CONCLUSION}

The current study sought to provide insight into the process of introducing dialogic education in the argumentative writing classroom. It aimed at comparing formalist teaching, in which teachers emphasise the different aspects of argumentative writing, to dialogic education as a method that harnesses communication and students' work with language to promote their activity, deepen their thinking and enrich their understanding (Alexander, 2006).

The results of the study showed that both formalist and dialogic teaching improved students' argumentative writing. However, the deep analysis of the papers and the teaching and learning context proved the surpass of dialogic activities. Dialogic teaching was a precious tool which influenced significantly the students' argumentative writing as well as their knowledge about argumentation as genre and their mode of thinking and talking about reality. In the dialogic teaching outputs, the conventional, monophonic argumentative texts of the formalist group which represented only the opinion of its author on the topic as a response to or as a repetition of an 'authoritative voice', were replaced by "written polyphonic, heteroglot texts" in which the oral dialogue was transferred in the written texts, the voices of the others were transformed in counter-arguments and the internally persuasive speech of each student was expressed by rebuttal arguments that seek to empower, consciously, their personal opinion on the issue (Egglezou, 2016).

The augmentation in the dialogic teaching group does not reflect only the students' better awareness on the structural exigencies of the genre. Rather, it reveals that argumentation was internalized in students' minds as a wide dialogue between various polyphonic and heteroglot people, who express different opinions and interests that must be critically taken in account. Such a clash of different ideas, arguments and attitudes and the reflection on them extends students' knowledge of the world, deepens their way of thinking, contributes to the formation of their individual persuasive speech and reduces their speaking apprehension level as result of the exchange of ideas and arguments. As a result, further studies are necessary to investigate dialogic education with other different aspects of language learning. In addition, the role of dialogue in changing students' attitudes of different conceptualizations can be investigated as a means to change the system of personal beliefs.

\section{REFERENCES}

[1] Alexander, R. (2006). Towards dialogic teaching: Rethinking classroom talk. Cambridge, UK: Dialogos.

[2] Boyd, M. P., \& Markarian, W. C. (2011). Dialogic teaching: Talk in service of a dialogic stance. Language and Education, 25 (6), 515-534.

[3] Brown, J. D. (2001). Using surveys in language programs. Cambridge, UK: Cambridge University Press.

[4] Dornyei, Z. (2003). Questionnaires in second language research: Construction, administration and processing. Mahwah, NJ: Erlbaum.

[5] Echevarria, S.D. \& Powers, K. (2006). School reform and standards-based education: A model for English language learners. Journal of Educational Research, 99 (4), 195-210.

[6] Egglezour, F. (2016). Bakhtin's influence: A Dialogic approach to teaching of argumentation. Journal of Mother Tongue Education, 4(1): 1-14.

[7] Gurevitch, Z. (2000). Plurality in dialogue: A comment on Bakhtin. Sociology 34 (2), 243-263.

[8] Haneda, M. (2016). Dialogic learning and teaching across diverse contexts: Promises and challenges. Language and Education, DOI: 10.1080/09500782.2016.1230128.

[9] Haneda, M., \& Wells, G. (2008). Learning an additional language through dialogic inquiry. Language and education, 22(2), 114-136.

[10] Hawkins, M. (2004). Researching English language and literacy development in schools. Educational Researcher 33 (3), $365-$ 384.

[11] Higham, R. J. E., Brindley, S., \& Van de Pol, J. (2014). Shifting the primary focus: Assessing the case for dialogic education in secondary classrooms. Language and Education, 28 (1), 86-99.

[12] Hosp, J. L. (2010). Linking assessment and instruction: Teacher preparation and professional development. TQ Connection Issue Paper. National Comprehensive Center for Teacher Quality.

[13] Juzwik, M. M., Borsheim-Black, C., Caughlan, S., \& Heintz, A. (2013). Inspiring dialogue: Talking to learn in the English classroom. New York, NY: Teachers College Press.

[14] Leer, E. B., \& Runck, B. C. (2016). Using writing workshop with English language learners. English Journal, $105(3), 107$.

[15] Lyle, S. (2008). Dialogic teaching: Discussing theoretical contexts and reviewing evidence from classroom practice. Language and education, 22 (3), 222-240.

[16] Maine, F. (2015). Dialogic readers: Children talking and thinking together about visual texts. London: Routledge.

[17] McCann, T. M. (2010). Gateways to writing logical arguments. English Journal, 33 (9). 103-115.

[18] Mercer, N. (2007). Dialogic teaching in science classrooms: Full Research Report. ESRC End of Award Report, RES-000-230939-A. Swindon: ESRC.

[19] Nagle, B., \& Williams, N. (2013). Methodology brief: Introduction to focus groups. Center for Assessment, Planning and Accountability, 1-12.

[20] National Research Council. (2000). How people learn: Brain, mind, experience, and school. Washington, DC: National Academy Press. 
[21] Newell, G., VanDerHeide, J., \& Wynhoff Olsen, A. (2014). High school English language arts teachers' argumentative epistemologies for teaching writing. Research in the Teaching of English, 49 (3), 95-118.

[22] Nystrand, M. (1997). Opening Dialogue: Understanding the Dynamics of Language and Learning in the English Classroom. New York: Teacher College Press.

[23] Nussbaum, E. M., \& Schraw, G. (2007). Promoting argument-counterargument integration in students' writing. The Journal of Experimental Education, 76 (1), 59-92.

[24] Peregoy, S. F., Boyle, O. F., \& Phillabaum, S. (2007). Reading, writing, and learning in ESL: A resource book for K-12 teachers. TESOL Quarterly, 41(1), 214.

[25] Sedova, K., Salamounova, Z., \& Svaricek, R. (2014). Troubles with dialogic teaching. Learning, Culture and Social Interaction, 3(4), 274-285.

[26] Skidmore, D. (2006). Pedagogy and dialogue. Cambridge Journal of Education. 36 (4), 503-514.

[27] Teo, P. (2016). Exploring the dialogic space in teaching: A study of teacher talk in the pre-university classroom in Singapore. Teaching and Teacher Education, 56 (2), 47-60.

[28] VanDerHeide, J., Juzwik, M., \& Dunn, M. (2016). Teaching and Learning Argumentation in English: A Dialogic Approach. Theory Into Practice, 55 (4), 287-293.

[29] Watkins, C. (2005). Classrooms as Learning Communities: What's in It for Schools? London: Routledge.

[30] Wegerif, R. (2011). Towards a dialogic theory of how children learn to think. Thinking skills and creativity, 6 (3), $179-190$.

[31] Wilkinson, I. A., Reznitskaya, A., Bourdage, K., Oyler, J., Glina, M., Drewry, R., \& Nelson, K. (2017). Toward a more dialogic pedagogy: changing teachers' beliefs and practices through professional development in language arts classrooms. Language and education, 31(1), 65-82.

[32] Winn, M. T., \& Johnson, L. P. (2011). Writing instruction in the culturally relevant classroom. Urbana, IL: National Council of Teachers of English.

[33] Wegerif, R. (2011). “Towards a Dialogic Theory of How Children Learn to Think.” Thinking Skills and Creativity. 6 (3), 179190.

Hany Ibrahim Musa, Ph.D. TEFL, University of Exeter, as a dedicated foreign language educator and advocate, he is an expert researcher with 10+ years of experience in academic publishing in Al-Azhar University in Egypt and Qassim University in KSA. Topics he is interested in are related to language education in general and EFL education in particular. 